\title{
DIREITOS DA PERSONALIDADE E O TELETRABALHO: A VULNERABILIDADE DO TRABALHADOR E OS IMPACTOS LEGISLATIVOS
}

\author{
Dirceu Pereira Siqueira \\ Centro Universitário de Maringá (Unicesumar), Paraná \\ dpsiqueira@uol.com.br \\ Danilo Henrique Nunes \\ Centro Universitário da Fundação Educacional de Barretos \\ (UNIFEB), São Paulo \\ dhnunes@hotmail.com
}

\begin{abstract}
RESUMO: O presente artigo abordará sobre o instituto do teletrabalho, modalidade de trabalho prestado à distância, em local diverso da sede do empregador, desempenhado através de meios telemáticos e informatizados de comando, cuja abordagem tornou-se imprescindível, dada a recentíssima alteração na Consolidação das Leis do Trabalho (CLT), perpetrada pela Lei $n^{\circ}$ 13.467/17, que passou a regulamentar o tema especificamente no sistema normativo pátrio. Entretanto, o que poderia ser considerado louro para os direitos sociais, tornou-se uma derrota, ante a supressão de garantias e afrontas principiológicas inserida malevolamente em seu bojo, ato imperdoável, dada a notória inspiração no Código do Trabalho Português (CTP), que detém umas das mais avançadas regulamentações do mundo, a qual fora concomitantemente observada e negligenciada pelo Congresso Nacional, visto que derrogou direitos e desconsiderou princípios basilares incidentes ao direito do trabalho, provocando implicações jurídicas, que o presente estudo elencará ao final soluções alternativas. Em síntese, a respectiva pesquisa guiou-se pelo método dedutivo, com base em livros, artigos científicos e publicações em periódicos eletrônicos. PALAVRAS-CHAVE: Regulamentação do Teletrabalho. Supressão de Direitos. Retrocesso Social.
\end{abstract}

Personality rights and telework: vulnerability of the worker and the legislative impacts

ABSTRACT: This article will focus on the telework institute, working mode provided at a distance, in a place other than the employer's headquarters, carried out by telematic and computerized means of command, whose approach has become indispensable, given the recent change in the Consolidation of Laws of Labor (CLT), perpetrated by Law 13467/17, which regulates the subject specifically in the normative system of the country. However, what could be considered fair to social rights, has become a loss, before the abolition of guarantees and principiológicas affronts inserted malevolently in its wake, an unforgivable act, given the notorious inspiration in the Portuguese Labor Code (CTP), which holds one of the most advanced regulations in the world, which was concomitantly observed and neglected by the National Congress, since it derogated rights and disregarded basic principles incident to labor law, provoking legal implications that the present study will in the end endorse alternative solutions. In summary, the respective research was guided by the deductive method, based on books, scientific articles and publications in electronic journals.

KEYWORDS: Regulation of Telework. Suppression of Rights. Social retraction. 


\section{INTRODUÇÃO}

O trabalho, por ser inerente ao homem, sujeita-se às alterações provocadas pelos avanços tecnológicos de informação e comunicação, especialmente na era globalizada. Por esta razão, as normas trabalhistas brasileiras, outrora fixadas, entram no centro do debate sob o argumento de que, a tecnologia as teria ultrapassado e as leis em vigência já não são mais aptas a retratarem de forma fidedigna a atual realidade diante de tais progressos.

Assim, surge a necessidade de alterações legislativas, bem como novas previsões legais, capazes de retratar o período vivenciado e tutelar as novas espécies laborativas despertadas a princípio, a qual foi atendida num primeiro momento pelo legislador pátrio, mediante o PCL $\mathrm{n}^{\circ}$ 38/2017, que se tornou a Lei Federal $n^{\circ} 13.467 / 2017$, conhecida amplamente como Reforma Trabalhista.

Ocorre que a inovação legislativa alterou inúmeros dispositivos legais contidos na Decreto-Lei ${ }^{\circ} 5.452$ de $1^{\circ}$ de maio de 1943 - Consolidação das Leis do Trabalho, doravante chamada CLT, como regulamentou temas até então não previstos expressamente no arcabouço trabalhista, dentre eles, o teletrabalho objeto do presente estudo. Para tanto, sob o método hipotético-dedutivo, este caminhará no sentido de elucidar a sua conceituação, trará a luz os seus pressupostos configuradores, os seus primeiros indícios, adesões em âmbito nacional, características, divisões, além da disciplina jurídica a ele aplicada antes da novatio legis.

Sucessivamente, abordar-se-á regulamentação no seio da lei supradita e suas implicações derivadas, em seguida apresentará a norma inspiradora do legislador pátrio e tecer-se-á um comparativo quanto a positivação realizada em relação ao espelho que se dispunha.

Em resumo, o respectivo estudo pretende levar a reflexão sobre o tema, quanto a previsão legal imposta, suas implicações jurídicas no que tange a violação de direitos e garantias fundamentais celetistas, com propósito de encontrar possíveis soluções para problemática que se instaura, através de análise axiológica dos princípios que foram suprimidos, além de contribuir para os debates sobre o tema.

\section{Do TEletrabalHo}

Inicialmente faz-se necessário a compreensão da palavra teletrabalho, que possui como prefixo a palavra tele de origem etimológica grega, cujo significado é distância, desta forma sua acepção deve ser compreendida como trabalho à distância.

No entanto, cabe esclarecer que emprego de tal terminologia decorre da forma de prestação de serviço (relações laborativas) tendo as inovações tecnológicas de informação como meio, as quais dinamizaram a relação clássica trabalhista e, hodiernamente encontram-se consolidada no mundo empresarial e regulamentada em vários países, por isso torna-se crucial tecer breves considerações sobre o seu instituto (BARROS, 2017, p. 214).

Diante do cenário apresentado, o legislador viu-se no dilema de tratar do tema em comento, promovendo tal Reforma legislativa, contudo, sem amplo debate na sociedade, sendo assim, objeto de constantes questionamentos e de relevantes controvérsias doutrinárias. 


\subsection{O surgimento do teletrabalho e suas primeiras adesões}

$\mathrm{Na}$ atualidade muito se debate, quanto a origem do teletrabalho, todavia esta não tem uma resposta uníssona entre os doutrinadores e historiadores do direto, por esta razão o presente trabalho ficará imbuído de demonstrar o seu idealizador. Dessarte, historicamente atribui-se a paternidade deste instituto a Jack Nilles (HERNANDEZ, 2007. p. 71), Secretário do Comitê de Investigação da Aerospace Corporation, localizado ao sul da Califórnia, o qual era responsável por desenhar veículos espaciais para o Departamento de Defesa (Força aérea) e para a NASA (RODRIGUES, 2011, p. 27).

De acordo com os registros, no ano de 1971 Nilles fora questionado por uma das autoridades locais como era possível o centro espacial colocar o homem na Lua, mas não conseguir resolver problemas com o trânsito e engarrafamentos que assolava toda a população. Ante tal inquirição, insurgiu com a ideia de transmutar a relação clássica de trabalho em telework (RODRIGUES, 2011, p. 27), porém esta não fora bem aceita por seus superiores, sob a justificativa de que era preciso investigações preliminares, bem como uma mudança de hábito de toda uma população.

Nos anos seguintes, a procura de auxílio para a realização da ideia apontada, desligou-se Aerospace e, entre os anos de 1972 a 1973, passou a ocupar o cargo de Diretor de Desenvolvimento de Programas Interdisciplinares na Universidade do Sul da Califórnia, momento em que veio a implantar o Programa de Permuta entre Transportes e Telecomunicação, que tinha como objetivo diminuir e/ou elidir os deslocamentos diários dos empregados até os locais de trabalho (RODRIGUES, 2011, p. 28).

Diante tal iniciativa e o êxito logrado, fora requisitado para implementá-lo em inúmeras empresas norte americanas, listadas entre as 100 (cem) mais famosas pela revista Fortune no ano de 1974 (RODRIGUES, 2011, p. 28), uma vez que este auxiliava na retenção do custeio empresarial e medrava-se o lucro, cujos fatores foram essenciais para a sua disseminação mundo afora no séc. XXI. Até se propagar no Brasil, tanto que na década de noventa o Conselho Regional de Administração de São Paulo, engendrou o grupo SOBRATT - Sociedade Brasileira de Teletrabalho e Teleatividades (2018), sociedade civil sem fins lucrativos, que tem como máxima a disseminação do conhecimento sobre o tema, como também, os órgãos públicos nacionais passaram aderir ao teletrabalho a sua estrutura, como o Tribunal de Contas da União (TCU) pelas portarias no 139/2009 e 99/2010; o Tribunal Superior do Trabalho (TST) em 2012, por intermédio da Resolução no 1.499; a Controladoria-Geral da União (CGU) em 2015 e, por fim o Conselho Nacional de Justiça (CNJ) através da Resolução $n^{\circ} 227$, regulamentando em toda esfera do Poder Judiciário. Do mesmo modo, as empresas privadas, como as renomadas empresas: Gol Linhas Aéreas, O Boticário, Shell, Del etc. (TIMO, 2018).

Depreende-se que embora tenha ocorrido tal fenômeno, suscita-se que até o ano de 2017 o Brasil carecia de legislação específica sobre a novel espécie de trabalho que se despertava, o que não foi nenhum empecilho para a sua exponencial adesão, nos diversos segmentos empresariais como acima listado.

\subsection{Noções gerais do teletrabalho}

Considerando-se a relevância da presente pesquisa, é vital que haja percepção de suas características, já que tal fator possibilitará uma melhor compreensão e reflexão sobre o tema proposto. 
Dessa maneira, precipuamente há de se destacar que teletrabalho constitui uma das espécies de contrato de trabalho existentes na seara trabalhista, conhecido como trabalho a distância, pois o seu desenvolvimento se dá em ambiente virtual (LEITE, 2017, p. 211) e longínquo do escritório central e/ou centro de produção, conforme preleciona Organização Internacional do Trabalho - OIT (COLNAGO, 2017, p. 779), através de computadores, internet, redes sociais, celulares, fax, e-mail etc. (NASCIMENTO; NASCIMENTO, 2014, p. 778), cujas ferramentas ensejam a desnecessidade da presença física do trabalhador na sede do empregador, como outrora era difundido para a consecução da relação de emprego.

Diante tal fato, e por seu exercício via de regra dar-se em domicílio, inúmeros autores passaram afirmar que houve o renascimento do trabalho, instigado pelas modernas tecnologias, haja vista o tradicional consisti no desenvolvimento de artesanatos ou de pequena indústria caseira - manufatura, enquanto o contemporâneo compreende aquele que se vale das novas tecnologias, Alice Monteiro de Barros (2017, p. 214) pontua:

\begin{abstract}
O teletrabalho distingue-se do trabalho a domicílio tradicional não só por implicar, a realização de tarefas mais complexas do que as manuais, mas também porque abrange setores diversos como: tratamento, transmissão e acumulação de informações; atividade de investigação; secretariado, consultoria, assistência técnica e auditoria; gestão de recursos, vendas e operações mercantis em geral; desenho, jornalismo, digitação, redação, edição, contabilidade, tradução, além da utilização de novas tecnologias, como informática e telecomunicação, afetas ao setor terciário.
\end{abstract}

Desta feita, cabe esclarecer que o teletrabalho vem a ser aquele executado via mecanismos tecnológicos, podendo apresentar as seguintes divisões: a) teletrabalho em domicílio: desenvolvido na residência, casa, habitação ou moradia do próprio empregado (MARTINS, 2012, p. 27); b) teletrabalho em telecentros: consiste no exercício da prestação de serviços em espaços previamente preparados pelo próprio empregador, fora da sede da empresa como coworking, ou seja, escritórios compartilhados (SILVA, 2018); e, c) teletrabalho nômade, móvel ou itinerante: desenvolvido comumentemente dentro de outras empresas, diversa da empregadora, de resto não possui um local predeterminado para a prestação de serviços (SILVA, 2018, p. 106).

Desse modo, atividade laboral realizada singularmente por pessoa física com a utilização de novas tecnologias de informação e comunicação fora dos limites físicos da empresa credora do trabalho, são pressupostos inexoráveis para a configuração de sua espécie de trabalho, porém desde já frisa que o presente estudo se refere necessariamente ao teletrabalho desempenhado no próprio domicílio do empregado.

\title{
1.3. Disciplina jurídica do teletrabalho antes da Lei $13.467 / 17$
}

Em análise da CLT até o ano de 2017 nota-se a ausência de regulamentação específica sobre o teletrabalho, mas realizando a exegese das normas nela positivadas verifica-se as disciplinas jurídicas a ele incidente. Já que a legislação em comento desde de $1^{\circ}$ de maio de 1943 sempre tratou de forma isonômica o trabalho realizado no estabelecimento do empregador e o executado em domicílio, nos termos do art. $6^{\circ}$ da CLT $^{1}$, e para tanto, bastava o preenchimento dos pressupostos ou elementos fáticos jurídicos caracterizadores da relação de emprego (GONÇALVES, 2018), definidos no art. $3^{\circ}$ da CLT $^{2}$.

\footnotetext{
1 Art. 6o Não se distingue entre o trabalho realizado no estabelecimento do empregador e o executado no domicílio do empregado, desde que esteja caracterizada a relação de emprego.

2 Art. $3^{\circ}$. Considera-se empregado toda pessoa física que prestar serviços de natureza não eventual a empregador, sob a dependência deste e mediante salário.
} 
Contudo, mesmo com a previsão aludida, os operadores e aplicadores do direito se deparavam com uma grande dificuldade, qual seja, a comprovação da subordinação jurídica, eis que não havia como atestar o comando pessoal e direito do empregador na presente espécie de trabalho, por inexistência de previsão legal apta a configurá-la.

Diante da lacuna aventada, quanto ao modo de comprovação da subordinação das atividades desenvolvidas a distância, através de meios telemáticos e informáticos de comando, tevese inúmeras discussões doutrinárias e jurisprudencial sobre a matéria, a vista que num primeiro momento tinha-se uma enorme gama de trabalhadores desprotegidos, por não estarem abarcados pelo vínculo de emprego e, segundo uma implícita evasão arrecadatória tributária.

Até que no dia 15 de dezembro de 2011, época em que adveio a Lei no 12.551 e passou a incorporar ao art. $6^{\circ}$ da $\mathrm{CLT}^{3}$, os conceitos relativos à subordinação estrutural - comando a distância - equiparando-a ao comando direto e pessoal (DELGADO, 2017, p. 1024), dando início a uma incipiente regulamentação.

Assim, em razão da implementação suscitada, cessou-se a discussão que perpetuava quanto a subordinação, vista a expressa previsão normativa dos meios aptos a viabilizar o reconhecimento do liame empregatício, que por sinal são tênues, pois segundo Pinho Pedreira (2000, P. 586) "a prestação de serviços do teletrabalhador pode assumir tanto a figura autônoma quanto subordinada, devido a sua fronteira habitada, denominada como zona grise" (BARROS, 2017, p. 212).

Percebe-se que a previsão legal demonstrada, cumpriu num primeiro momento com sua finalidade precípua e secundária, a vista que conseguiu garantir os direitos mínimos dos teletrabalhadores, mediante a equiparação realizada deste, com o empregado sob o regime comum, igualmente possibilitou a arrecadação tributária diante o liame empregatício que se passou a configurar.

Não obstante, o legislador brasileiro, não se deu por satisfeito com esta, pois ansiava por uma previsão legal específica e, sob o manto de ampliar e consolidar os direitos e garantias de tais profissionais, que por ora, já estavam abarcadas, elaborou e aprovou lei ordinária federal, alterando sistematicamente e profundamente toda construção protecionista que até então se tinha, fazendo insurgir conflitos normativos e principiológicos.

\section{A REgulamentaÇÃo do TELETRABAlHo NA REFORMA TRABA- LHISTA}

Toda regulamentação de lei, deveria ter como premissa a criação de instrumento de exclusão, segregação e sedimentação da deplorável desigualdade entre pessoas e grupos sociais, reunindo às diretrizes constitucionais relativas aos direitos e garantias fundamentais no campo justrabalhista. Contudo, lamentavelmente a presente, resultante da Lei $n^{\circ} 13.467 / 17$, caminhou em sentido contrário as máximas trabalhistas e seus princípios delineadores em relação a regulamentação do teletrabalho, como será demonstrado.

\footnotetext{
3 Art. $6^{\circ}$ Não se distingue entre o trabalho realizado no estabelecimento do empregador, o executado no domicílio do empregado e o realizado a distância, desde que estejam caracterizados os pressupostos da relação de emprego. Parágrafo único. Os meios telemáticos e informatizados de comando, controle e supervisão se equiparam, para fins de subordinação jurídica, aos meios pessoais e diretos de comando, controle e supervisão do trabalho alheio.
} 


\subsection{Dos conflitos instaurados}

Em primeiro lugar salienta-se que será abordado os dispositivos criados e concomitantemente suas afrontas a princípios e/ou normas celetista, indicando seus pontos centrais e as polêmicas a eles inerentes.

Conforme analisado anteriormente, antes do surgimento da Lei $\mathrm{n}^{\circ} 13.467 / 17$, intitulada como Reforma Trabalhista, o ordenamento jurídico pátrio, em especial a CLT, não possuía previsão específica acerca do teletrabalho (MIESSA, 2017, p. 216), até o dia 11 de novembro de 2017, data em que entrou em vigor a novatio legis e criou o Capítulo II-A, destinado exclusivamente a tratar e regulamentar o tema, entre os arts.75A a 75E.

A princípio o art. 75-A da $\mathrm{CLT}^{4}$, dispõe sobre as regras a serem aplicadas ao empregado sob regime de teletrabalho, sem grande expressão, por conseguinte na forma do art. 75-B da CLT $^{5}$ instaurado, restou-se estabelecido que o teletrabalho não se configurará como atividade externa, embora seja desenvolvida fora das dependência do empregador, o que resulta numa incoerência dicotômica textual.

Não bastando, o mesmo artigo se valeu de um termo incomum ao direito do trabalho que é o preponderante, ou seja, ainda que o teletrabalhador venha a trabalhar cinquenta e um por cento de sua jornada de trabalho no regime presencial e o remanescente a distância, este será considerado para todos os efeitos como um teletrabalhador a rigor da lei, porém cabe arguir como haverá tal mensuração, já que este não se submete ao controle de jornada, nos termos do art. 62, III da CLT $^{6}$, incluído pela reforma.

Assim, a doutrina em tal circunstância, tem se posicionado no sentido de que apesar da exclusão expressa, o controle e a fiscalização da jornada deverá ser realizada, por meio dos mecanismos informatizados como e-mails, WhatsApp, Facebook, GPS, telefones, login e de logout, os quais são efetivos a controlar o tempo real despendido de labor, posto que se verificado que o credor do trabalho detinha condição para tanto e não o fez, ficará responsabilizado pelas verbas trabalhistas aplicada ao regime comum (CORREIA, 2018, p. 232).

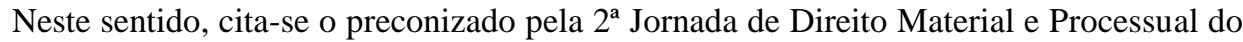
Trabalho (2018):

TELETRABALHO. CONTROLE DE JORNADA. As hipóteses de inaplicabilidade dos limites constitucionais de jornada de trabalho são excepcionais e restritas às situações em que o controle do horário não é possível, de modo que o inciso III do artigo 62 da CLT (incluído pela Lei $n^{\circ} 13.467 / 2017$ ) deve ser aplicado somente nos casos em que os empregados em regime de teletrabalho possuam atividade verdadeiramente incompatível com o controle de jornada. Nos demais casos em que o controle for possível, inclusive por meios telemáticos e informatizados, como autoriza o parágrafo único do artigo $6^{\circ}$ da CLT, não incide a nova regra trazida pelo inciso III do artigo 62 da CLT.

4 Art. 75-A. A prestação de serviços pelo empregado em regime de teletrabalho observará o disposto neste Capítulo.

5 Art. 75-B. Considera-se teletrabalho a prestação de serviços preponderantemente fora das dependências do empregador, com a utilização de tecnologias de informação e de comunicação que, por sua natureza, não se constituam como trabalho externo.

6 Art. 62 - Não são abrangidos pelo regime previsto neste capítulo: I - os empregados que exercem atividade externa incompatível com a fixação de horário de trabalho, devendo tal condição ser anotada na Carteira de Trabalho e Previdência Social e no registro de empregados; II - os gerentes, assim considerados os exercentes de cargos de gestão, aos quais se equiparam, para efeito do disposto neste artigo, os diretores e chefes de departamento ou filial; III - os empregados em regime de teletrabalho. 
Entretanto, apesar dos posicionamentos trazidos, não há jurisprudência corroborando-os, o que inexoravelmente remete ao campo das incógnitas e incertezas, restando ao judiciário juslaboral tomar posição sob tal dogmática jurídica instaurada.

Ademais, quanto ao art. $75-\mathrm{C}, \S \S 1^{\circ}$ e $2^{\circ}$ da $\mathrm{CLT}^{7}$, que autoriza a alteração entre os regime presencial para o teletrabalho mediamente mútua acordo entre as partes envolvida na contratação ou, somente pela vontade do empregador, no caso de determinação para o retorno ao regime presencial antes exercido, deve ser respeitado o disposto em seus parágrafos, ou seja, confecção de um aditivo contratual e o transcurso de no mínimo quinze dias computados da data da notificação (MIESSA, 2018, p. 232).

Conquanto, infere-se no tipo legal exposto problemas a serem percorridos e enfrentados, a vista que inexiste previsão de eventual penalidade a ser imposta em caso de descumprimento do prazo estabelecido, assim como, exigência de justificativas para tais transições (MIESSA, 2018, p. 220), circunstâncias das quais possivelmente afrontará o art. 468 da CLT ${ }^{8}$ e consequentemente o princípio da condição mais benéfica, conhecido também como da inalterabilidade contratual in pejus, visto que só é lícita a alteração contratual que não resultar em prejuízos diretos ou indiretos, sob pena de nulidade das cláusulas infringentes (MARTINEZ, 2011, p. 84), oriunda da nova jus variandi constituída pela Reforma (CORREIA, 2018, p. 240).

A título ilustrativo imaginem o seguinte caso hipotético: Alcebíades Xavier, contratado pela empresa X, para laborar na função de tradutor em regime presencial na cidade de Barretos$\mathrm{SP}$, passando o respectivo contrato firmado entre as partes a produzir os seus efeitos, posteriormente seu empregador decide alterá-lo para o regime de teletrabalho, após a sua concordância. Já como teletrabalhador, vem a prestar o vestibular da UFB (Universidade Federal de Brasília) com o intuito de ingressar na graduação de seus sonhos, o qual é aprovado. Diante de tal fato, muda-se para Brasília, uma vez que o seu trabalho não é empecilho, mas quando já estabelecido no planalto central é surpreendido com uma requisição de retorno ao regime anterior ocupado, situação que lhe dará apenas duas opções, retornar ou pedir dispensa. Pelo exemplo supra, embora haja a concordância do empregado, esta facilmente poderá ser descaracterizada, vez que este não tem outra alternativa senão aceitar, pois se recusar estará sujeito ao risco do desemprego. Da mesma maneira, nota-se de forma clarividente o ultraje ao princípio-regra supratranscrito inalterabilidade contratual in pejus - em consequência do poder concedido ao empregador, já que o empregado experimentará graves danos relativos as adaptações realizadas, a graduação a ser preterida ou até mesmo o desemprego a ser enfrentado.

No entanto, ainda que seja uma situação hipotética, esta infelizmente será a mais triste realidade de milhões de teletrabalhadores, que estarão submetido ao novo poder de mando, cuja solução apontada pela doutrina seria a aplicação analógica (MIESSA, 2017, p. 220) do art. 469 da CLT $^{9}$, todavia o seu cabimento ou não, ficará a mercê da hermenêutica dos nobres magistrados, de acordo com cada caso concreto a ser apreciado, o que comportará decisões distintas para

7 Art. 75-C. A prestação de serviços na modalidade de teletrabalho deverá constar expressamente do contrato individual de trabalho, que especificará as atividades que serão realizadas pelo empregado: $§ 1$ 을 Poderá ser realizada a alteração entre regime presencial e de teletrabalho desde que haja mútuo acordo entre as partes, registrado em aditivo contratual; $\S 2^{\text {o }}$ Poderá ser realizada a alteração do regime de teletrabalho para o presencial por determinação do empregador, garantido prazo de transição mínimo de quinze dias, com correspondente registro em aditivo contratual.

8 Art. 468. Nos contratos individuais de trabalho só é lícita a alteração das respectivas condições por mútuo consentimento, e ainda assim desde que não resultem, direta ou indiretamente, prejuízos ao empregado, sob pena de nulidade da cláusula infringente desta garantia.

9 Art. 469 - Ao empregador é vedado transferir o empregado, sem a sua anuência, para localidade diversa da que resultar do contrato, não se considerando transferência a que não acarretar necessariamente a mudança do seu domicílio. 
situações semelhantes, logo a insegurança jurídica. Por seu turno, o art. 75-D da CLT ${ }^{10}$, definiu que a responsabilidade pela aquisição dos equipamentos necessários para o desempenho do teletrabalho e as despesas dele decorrente deve estar prevista em contrato expresso, o que demonstra a imprecisão da lei, dado que deixa dúvidas a quem caberá o custo da compra. Demais disso, sua redação não se coadunar com a diretriz geral da CLT, a qual estabelece que os custos e encargos no tocante ao contrato de trabalho é de incumbência do empregador e jamais do empregado (DELGADO, 2017, p. 223), entendimento que deflui do conceito consagrado no art. $2^{\circ}$ da CLT $^{11}$ e do princípio da alteridade (SARAIVA; SOUTO, 2018, p. 33), ambos olvidados pelo legislador ordinário, como também o princípio do contrato realidade ou primazia da realidade (DELGADO, 2017), o qual retrata de forma indubitável a prática concreta da prestação de serviços ao longo da contratação, inobstante a vontade aventada na relação jurídica firmada.

Não podendo ser diferente o último art. 75-E da CLT $^{12}$, dispõe sobre o meio ambiente, transferindo ao teletrabalhador o ônus de cuidar de sua adequação, para inibir doenças ocupacionais e acidentes de trabalho, incumbindo unicamente ao empregador orientá-lo e colher a respectiva assinatura no termo de compromisso. Contudo, ainda que haja tal previsão, esta não exime o empregador da atribuição de cumprir e fazer cumprir as normas de segurança e medicina de trabalho (MIESSA, 2017, p. 222), conforme previsão estatuída no art. 157 da CLT ${ }^{13}$, ora esquecida pelo Congresso Nacional, na fugaz tentativa de transferir os riscos derivados do ambiente de trabalho ao hipossuficiente.

Assim a exegese que se faz com base na regulamentação apreciada é de uma nítida segregação normativa da premissa maior do direito do trabalho, que é garantir os direitos mínimos trabalhistas oriundos de segunda dimensão, dado que caminhou lastimavelmente em descompasso com os avanços já galgados, bem como desconsiderou pontos cruciais da norma inspiradora que será externada, os quais seriam aptos a obstarem os conflitos instaurados supraditos.

\subsection{Da inspiração normativa}

É cediço o fato de que o Brasil não foi o primeiro país a adotar o teletrabalho como uma espécie de contrato de trabalho, tanto que antes de sua regulamentação o país buscou inspiração normativa em legislações esparsas.

Dentre os países que serviram de modelo para a realização de tal feito segundo Geraldo Magela (2018), tem-se o Código do Trabalho Português, doravante CTP (PORTUGAL, LEI 7/2009, 2018), o qual possui uma das mais avançadas normas sobre o tema. Por esta razão, abordar-se-á os artigos relacionados com a regulamentação no compêndio celetista pátrio supramencionado, com fito a evidenciar os equívocos perpetrados. Deste modo, cumpre salientar que em fevereiro de 2009, por meio da Lei 99/2003 os lusitanos passaram a tratá-lo de forma específica em seu Código do Trabalho (WULFING, 2014, p. 158), o qual instituiu e estabeleceu em seu art. 165, que o teletrabalho compreende a prestação laboral realizada com subordinação jurídica,

${ }^{10}$ Art. 75-D. As disposições relativas à responsabilidade pela aquisição, manutenção ou fornecimento dos equipamentos tecnológicos e da infraestrutura necessária e adequada à prestação do trabalho remoto, bem como ao reembolso de despesas arcadas pelo empregado, serão previstas em contrato escrito. Parágrafo único. As utilidades mencionadas no caput deste artigo não integram a remuneração do empregado.

11 Art. $2^{\circ}$ - Considera-se empregador a empresa, individual ou coletiva, que, assumindo os riscos da atividade econômica, admite, assalaria e dirige a prestação pessoal de serviço.

12 Art. 75-E. O empregador deverá instruir os empregados, de maneira expressa e ostensiva, quanto às precauções a tomar a fim de evitar doenças e acidentes de trabalho.

13 Art. 157. Cabe às empresas: I - cumprir e fazer cumprir as normas de segurança e medicina do trabalho. 
habitualmente fora da empresa e através do recurso informáticos e telemáticos. Previsão normativa extremamente feliz, basta ver o termo da habitualidade empregada, que remete a constância e regularidade na prestação de serviços (LEITE, 2017, p. 162).

Além disso, o empregado em regime comum/presencial poderá passar a exercer o teletrabalho, para tanto, basta requerimento e que atividade desempenhada seja compatível com o regime especial, cuja solicitação não poderá ser obstada pelo empregador, em harmonia com o art. 166 do CTP. Portanto, suscita-se que em tal hipótese, o contrato deve ser escrito e conter os seguintes requisitos: identificação, assinaturas e domicílio ou sede das partes; indicação da atividade a ser prestado com menção expressa do regime e sua retribuição; indicação do período normal de trabalho, porém se este for inferior ao duração previsível do contrato de trabalho, deve conter a atividade a ser exercida após o seu término; a propriedade dos instrumentos de labor e o responsável pela a instalação e manutenção e o respectivo pagamento das despesas derivadas do consumo e utilização; identificação da empresa credora do trabalho e com quem o teletrabalhador deve se conectar no âmbito da prestação de serviço. Frisa-se que caso negado o requerimento e não constituído o contrato requerido ficará caracterizada grave e leve violação, de maneira respectiva, ante a inobservância dos preceitos alusivos positivados.

Não bastando, a legislação em análise fixa no rol do art. 167, a duração inicial do contrato de teletrabalho, o qual não pode ser excedente a três anos ou prazo diverso definido em instrumento coletivo, podendo qualquer uma das partes denunciar o mesmo nos seus primeiros trinta dias de execução, aos órgãos competentes. Entanto, após o decurso estabelecido, o empregado retornará a sua atividade de origem, garantindo-lhe uma certa estabilidade durante este interregno, não ficando sujeito as vicissitudes patronais, ou afrontas ao princípio da alteração contratual lesiva (BASTOS, 2017, p. 101). Noutro aspecto, quanto aos instrumentos de trabalho caberá ao empregador fornecê-los, instalá-los, arcar com as despesas dele decorrentes e, estabelecer regras de utilização, funcionamento e destinação a serem observada pelo teletrabalhador, salvo se houver disposição contratual em sentido oposto, nos termos do art. 168 do $\mathrm{CTP}^{14}$.

Ademais como forma de assegurar a igualdade de tratamento entre o teletrabalhador e os demais empregados em regime comum, foi determinado no art. 169 do CTP que ambos detém os mesmos direitos e deveres, no que se refere a formação, promoção ou de carreira profissionais; limites de jornada; segurança; saúde no trabalho; reparação de danos emergentes oriundos de acidente de trabalho ou doença ocupacional e promoção do convívio dos trabalhadores com o objetivo de evitar o seu isolamento social (BASTOS, 2017, p. 103).

Outra previsão de suma importância pelo código em estudo, refere-se à privacidade do teletrabalhador, a qual deve ser respeitada de forma a garantir-lhe o tempo de descanso e o seu repouso, previsto no art. 170 do CTP, tal como o empregador só poderá visitá-lo das 09:00 às 19:00 horas, mediante acompanhamento do teletrabalhador ou terceiro indicado e, cuidou de forma exclusiva sobre a sua participação e representação coletiva, podendo este se candidatar a tal cargo e utilizar às tecnologias de informação a seu dispor, para participar de reuniões, bem como comunicar-se com os demais colegas de ofício.

Destarte, verifica-se que o direito português laboral, inspiração brasileira, melhor abordou o teletrabalho (BASTOS, 2017. p. 152), posto que tratou de forma expressa as suas peculiarida-

${ }^{14}$ Art. $168^{\circ}$. 1- Na falta de estipulação no contrato, presume -se que os instrumentos de trabalho respeitantes a tecnologias de informação e de comunicação utilizados pelo trabalhador pertencem ao empregador, que deve assegurar as respectivas instalação e manutenção e o pagamento das inerentes despesas. 
des, como a instalação, manutenção e responsabilidade pelas despesas advindas com os instrumentos de trabalho, cujo ônus via de regra recairá ao empregador, salvo disposição contratual em sentido contrário.

Em síntese, o direito lusitano não deixou de abordar temas cruciais como a privacidade e intimidade do empregado, de modo que o teletrabalho e o controle realizado pelo empregador não viesse as comprometê-las, questão estas dentre outras omitidas e/ou estabelecidas em contrassenso pela Reforma Trabalhista, equívoco imperdoável, dada a base regulamentar lusitana que se dispunha e foi embasada.

\section{DA RELEVANTE VERIFICAÇÃO DO INSTITUTO NO DIREITO COM- PARADO}

Consoante o ordenamento jurídico pátrio celetista atual relativo ao teletrabalho e a norma legislativa lusitana inspiradora, nota-se que o legislador brasileiro não foi fiel a sua inspiração, tampouco agregou valoração quando da regulamentação pátria, pois descumpriu com a premissa maior do sistema constitucional vigente, isto é, a proteção jurídica, conforme se suscitará.

Dado que, desprotege o teletrabalhador a partir do momento em que lhe excluí do controle da jornada, em decorrência da justificativa da impossibilidade de fiscalização, inobstante os avanços tecnológicos dispostos na sociedade contemporânea, cuja regressão não se opera no Código Português, que inclusive equiparou-lhe ao empregado comum para todos os efeitos legais. Acontece que tal supressão que decorreu por mera opção legislativa, desconsiderou toda uma conquista história, a norma inspiradora e, inclusive previsão constitucional e infraconstitucional preteritamente já estatuída nos arts. $7^{\circ}$, XIII da Lei Magna ${ }^{15}$ e 58 da CLT $^{16}$, o que passou a impossibilitar a percepção de horas extras, adicionais noturnos, intervalos intrajornadas e interjornadas, dentre outros direitos consagrados pela constituinte originário, sob o vil fundamento da autonomia horária concedida ao empregado (MIESSA, 2017, p. 219).

Saliente-se por não estar submetido ao controle de jornada, notoriamente ficará sujeito a um comando no mínimo desordenado, que indubitavelmente será acompanhada de condutas perniciosas como ligações frequentes, imposição de horários e metas a serem alcançadas, o que ensejará na transgressão aos direitos inerentes a sua condição humana (REIS, 2007, p. 106), estabelecidos no art. $5^{\circ}, \mathrm{X}$ da $\mathrm{CF} / 88^{17}$, ao contrário da legislação lusitana, a qual precavida, dispôs sobre onde, quando e como esta deverá ocorrer, conferindo maior proteção ao labutador frente aos avanços tecnológicos (BASTOS, 2017, p. 108), ao contrário sensu da nacional, que quedou-se sobre o tema embora o espelho que se tinha.

Ademais, em razão da atividade laboral se dar por meios telemáticos e informáticos de comando suceder-se-á hiperconexão, que coloca em risco o direito ao descanso do teletrabalhador, em virtude do credor do trabalho vir a procurá-lo em interregno que em tese seriam de ócio, para tratativa de questões relacionadas a labuta, situação da qual restaria configurado o regime de sobreaviso (BASTOS, 2017, p. 121), caso não houvesse o óbice legislativo acima elencado, isto é, a exclusão de controle de jornada, cuja situação nociva não se observa no direito ibérico.

${ }^{15}$ Art. $7^{\circ}$, XIII - duração do trabalho normal não superior a oito horas diárias e quarenta e quatro semanais, facultada a compensação de horários e a redução da jornada, mediante acordo ou convenção coletiva de trabalho.

${ }^{16}$ Art. 58. A duração normal do trabalho, para os empregados em qualquer atividade privada, não excederá de 8 (oito) horas diárias, desde que não seja fixado expressamente outro limite.

17 Art. $5^{\circ}$, X. são invioláveis a intimidade, a vida privada, a honra e a imagem das pessoas, assegurado o direito a indenização pelo dano material ou moral decorrente de sua violação. 
Acrescenta-se, que o novo jus variendi estabelecido pelo legislador regulamentador, ultraja o princípio da inalterabilidade contratual lesiva, em decorrência de inexistência de previsões de justificativas ou prazo para a prática de tal ato, oposto diametralmente a norma portuguesa, a qual fixa o lapso máximo de três anos ou diverso definido por instrumento coletivo de trabalho para permanência do exercício no regime especial em discussão, eis que sua previsão pauta-se pela segurança jurídica (AMADO, 2011, p. 145) da parte hipossuficiente da relação laboral, antagonicamente a norma pátria que lhe sujeita a intempérie patronal.

Outrossim, a aquisição de equipamentos para o desenvolvimento do trabalho, a priori, conforme previsão já apresentada, deve estar prevista em contrato expresso. Com isso, o legislador inverteu toda a lógica do sistema celetista, uma vez que assunção do risco da atividade econômica transmutou do explorador para o explorado. Em contrapartida, a norma espelhada imputa tal encargo ao beneficiário da exploração do trabalho (BASTOS, 2017, p. 102).

Por fim, neste comparativo não se pode deixar de salutar o meio ambiente telelaboral, abordado pela reforma regulamentadora, a qual teve o viés de imputar a responsabilidade por sua mantença, prevenção e precaução quanto a acidente de trabalho e doenças profissionais ao contratado, cuja aberratio não se faz presente na lei que se compara, devido a equalização de tratamento plenamente garantido e assegurado em seu direito.

Desta forma, a normatização em comento ponderada, denota-se inconstitucional, vez que fere o princípio da vedação ao retrocesso social, limitador das atuações do Estado, o qual veda atuações do Estado que tenha finalidade derrogatória de direito e garantias fundamentais ou sua mitigação (VASCONLECOS; LUIZ, 2018), como também avilta a ideia de progressividade dos direitos laborais contemplados no art. $7^{\circ}$, caput, da $\mathrm{CF} / 88^{18}$, segundo se nota. Em suma, a regulamentação específica do regime de teletrabalho que a princípio deveria ser considerado como uma conquista, infelizmente tornou-se pesadelo, haja vista deixaram os teletrabalhadores a limbo da tutela constitucional e, questões cruciais que deveriam e poderiam ter sido abordadas como o direito à intimidade, privacidade, fiscalização, dentre outros, foram simplesmente olvidados.

\section{CONSIDERAÇÕES FINAIS}

Ante todo o exposto, a pesquisa analisou a positivação do teletrabalho na CLT, demonstrando de forma lúdica, os eventuais equívocos cometidos pelo legislador nacional, responsável pela celeuma jurídica hoje instalada, objeto de debate acadêmico e doutrinário.

Assim, fora apresentado as suas características, terminologia, regulamentação e até mesmo instituto alienígena que deu amparo a norma atualmente consolidada, todavia não plagiada, consistindo quiçá na grande falha praticada.

Diante disso, a regulamentação provocada pela Lei $\mathrm{n}^{\circ} 13.467 / 17$, alterou toda conjuntura jurídica que até então se tinha instaurada, vez que a Lei $\mathrm{n}^{\circ} 12.511 / 11$ não fazia distinção entre teletrabalhador e empregado sob o regime comum, garantindo desta forma, a igualdade de tratamento normativo e direitos entre ambos. Entretanto, com o advento da previsão específica ocorreu o inverso. Não bastando, teve-se afrontado princípios norteadores da relação do trabalho, bem como supressões de direitos e garantias fundamentais, o que demonstrou uma notória desconsideração do legislador ao preceito basilar da progressão dos direitos sociais, que a rigor é de

${ }^{18}$ Art. $7^{\circ}$. [...] são direitos dos trabalhadores urbanos e rurais, além de outros que visem à melhoria de sua condição social. 
incumbência do Estado Democrático de Direito tutelá-los, por meio dos seus representantes legais, autores desta nefasta implementação.

Entretanto, ante o cenário atual e a perniciosidade da novatio legis, quanto a regulamentação do teletrabalho já retratada, o presente estudo levanta duas alternativas para o seu enfrentamento jurídico, a primeira delas consiste no ajuizamento de Ação Declaração de Inconstitucionalidade (ADIN), em razão das modificações reducionistas/abolicionistas trazidas pela reforma trabalhista, para que assim haja a derrogação dos novos regramentos positivados no regimento celetista. Já a segunda opção, em tese a mais propícia e viável a ser implementada, constitui na interpretação dos novos dispositivos instaurados pela reforma, à luz da constituição federal e dos princípios norteadores do direito laboral, ato que certamente obstará a perpetuidade da violação dos diretos trabalhistas, uma vez que o teletrabalhador carece de representatividade sindical.

Assim encarando a realidade atual, com base nos aspectos levantados sobre o tema, conclui-se que a reforma em hipótese alguma almejou a ampliação e a tutela dos direitos deste profissional, por esse motivo deve ser rechaçada por todos os profissionais do direito.

\section{REFERÊNCIAS}

AMADO, João Leal. Contrato de trabalho. 3 ed. Coimbra: Almeida, 2011. p. 145.

BARROS, Alice Monteiro de. Curso de direito do trabalho. 11. ed., Atual. por Jossé Claudio Franco de Alencar. São Paulo: LTr, 2017.

BASTOS, Mariana Candini. Teletrabalho, subordinação e seus reflexos: uma análise comparada entre Brasil e Portugal. 1 ed. Curitiba: Juruá, 2017.

BRASIL. Decreto-Lei $n^{\circ} 5.452$, de $1^{\circ}$ de maio de 1943. Aprova a Consolidação das Leis do Trabalho. Diário Oficial da União, Brasília, DF, 1 mai. 1943. Disponível em: http://www.planalto.gov.br/ccivil_03/Decreto-Lei/Del5452.htm. Acesso em: 28 ago. 2018.

BRASIL. [Constituição (1988)]. Constituição da República Federativa do Brasil. 3 ed. atual., ampl. e ver. Salvador: JusPodivm, 2018.

BRASIL. Lei n 13.467, de 13 de julho de 2017. Altera a Consolidação das Leis do Trabalho (CLT), aprovada pelo Decreto-Lei $n^{\circ} 5.452$, de $1^{\circ}$ de maio de 1943, e as Leis $n^{\circ} 6.019$, de 3 de janeiro de 1974, 8.036, de 11 de maio de 1990, e 8.212, de 24 de julho de 1991, a fim de adequar a legislação às novas relações de trabalho. Diário Oficial da União, Brasília, DF, 13 jul. 2017. Disponível em: http://www.planalto.gov.br/ccivil_03/_ato2015-2018/2017/lei/L13467.htm. Acesso em: 23 ago. 2018.

BRASIL. Lei $n^{\circ} 12.551$, de 15 de dezembro de 2011. Altera o art. $6^{\circ}$ da Consolidação das Leis do Trabalho (CLT), aprovada pelo Decreto-Lei $n^{\circ} 5.452$, de $1^{\circ}$ de maio de 1943, para equiparar os efeitos jurídicos da subordinação exercida por meios telemáticos e informatizados à exercida por meios pessoais e diretos. Diário Oficial da União, Brasília, DF, 15 dez. 2011. Disponível em: http://www.planalto.gov.br/ccivil_03/ato2011-2014/2011/lei/112551.htm. Acesso em: 19 ago. 2018.

COLNAGO, Lorena de Mello Rezende; CHAVES JUNIOR, José Eduardo de Resende; ESTRADA, Manuel Martín Pino. Teletrabalho. 1 ed. São Paulo: LTr, 2017. p. 779.

CORREIA, Henrique; MIESSA, Élisson. Manual da reforma trabalhista. 1 ed. Salvador: JusPODIVM, 2018. 
DELGADO, Mauricio Godinho. Curso de Direito do Trabalho. 16 ed. rev. e ampl. São Paulo: LTr, 2017.

DELGADO, Mauricio Godinho. A reforma trabalhista no Brasil: com os comentários à Lei n. 13.467/2017. 1 ed. São Paulo: LTr, 2017. p. 139.

GONÇALVES, G. et al. Evolução da legislação trabalhista para o teletrabalho. Revista Científica Integrada Unaerp Campus Guarujá, São Paulo, n. 3, p. 5, 2018. Disponível em: https:// www.unaerp.br/revista-cientifica-integrada/edicao-atual/2981-rci-evolucao-da-legislacao-trabalhista-para-o-teletrabalho-06-2018/file. Acesso em: 24 out. 2018.

LEHFELD, L.S; LÉPORE, P.E; FERREIRA. O.A. V.A.; Monografia Jurídica: guia prático para elaboração do trabalho científico e orientação metodológica. 2 ed. rev., atual. e ampl. Rio de Janeiro: Forense; São Paulo: Editora Método, 2015. 126p.

LEITE, Carlos Henrique Bezerra. Curso de Direito do Trabalho. 8 ed. São Paulo: Saravia, 2017.

MARTINEZ, Luciano. Curso de direito do trabalho: relações individuais, sindicais e coletivas do trabalho. 2 ed. São Paulo: Saraiva, 2011. p. 84.

MARTINS, Sergio Pinto. Comentários à CLT. 16 ed. São Paulo: Atlas, 2012. p. 27.

MELO, Geraldo Magela. O teletrabalho na nova CLT. Disponível em: https://www.anamatra.org.br/artigos/25552-o-teletrabalho-na-nova-clt. Acesso em: 17 set. 2018.

MIESSA, Élisson. A reforma trabalhista e seus impactos. 1 ed. Salvador: JusPODIVM, 2017.

NASCIMENTO, Amauri Mascaro; NASCIMENTO, Sônia Mascaro. Curso de Direito do Trabalho. 29 ed. São Paulo: Saraiva, 2014. p. 778.

PEDREIRA, Pinho. O teletrabalho. 1 ed. São Paulo: LTr, 2000. p. 586.

PORTUGAL. Lei $\mathbf{n}^{\mathbf{0}}$ 7/2009, de 12 de fevereiro. Aprova a revisão do Código do Trabalho. Disponível em: https://dre.pt/application/dir/pdf1s/2009/02/03000/0092601029.pdf. Acesso em: 26 ago. 2018.

REIS, Jair Teixeira dos. Subordinação jurídica e o trabalho à distância. 1 ed. São Paulo: LTr, 2007. p. 106.

RODRIGUES, Ana Cristina Barcellos. Teletrabalho: a tecnologia transformando as relações de trabalho. In: Dissertação de Mestrado - Departamento do Direito do Trabalho e da Seguridade Social da Universidade de São Paulo, 2011.

SARAIVA, Renato; SOUTO, Rafael Tonassi. Direito do trabalho concursos públicos. 20 ed. Salvador: 2018. p. 33.

SIQUEIRA, Dirceu Pereira; FERRARI, Caroline Clariano. O direito à informação como direito fundamental ao estado democrático. Revista Direitos Sociais e Políticas Públicas - Unifafibe. V. 4, N. 2, 2016.

SIQUEIRA, Dirceu Pereira; CASTRO, Lorenna Roberta Barbosa. Minorias e grupos vulneráveis: a questão terminológica como fator preponderante para uma real inclusão social. Revista Direitos Sociais e Políticas Públicas - Unifafibe. V. 5, N. 1, 2017. 
SILVA, Frederico Silveira e. O Teletrabalho como novo meio de laborar e sua compatibilidade com o ordenamento jurídico brasileiro. 2004. Disponível em: https://www.boletimjuridico.com.br/doutrina/artigo/306/o-teletrabalho-como-novo-meio-laborar-compatibilidade-comordenamento-juridico-brasileiro-. Acesso em: 28 ago. 2018.

SOBRATT. Cartilha sobre teletrabalho, home office, trabalho à distância. Disponível em: http://www.sobratt.org.br/site2015/wp-content/uploads/2017/01/1_010917_af_cartilha teletrabalho_apos_olimpiada1.pdf. Acesso em: 11 out. 2018.

TIMO, Desirée. Reflexões sobre o teletrabalho no Brasil: antes e depois da Lei n. 13.467/2017. 2017. Disponível em: http://www.sobratt.org.br/index.php/01092017-reflexoes-sobre-o-teletrabalho-no-brasil-antes-e-depois-da-lei-n-13-4672017/. Acesso em: 19 ago. 2018.

VASCONCELLOS, Mariana de Oliveira de; LUIZ, Fernando Vieira. Princípio da proibição do retrocesso social e sua importância na contemporaneidade. Revista da Emesc. Santa Catarina, ano 22, n. 28 ago. 2015. Disponível em: https://revista.esmesc.org.br/re/article/view/120/99. Acesso em: 19 set. 2018

WULFING, Juliana. Teletrabalho: proposta de regra jurídica fundamentada no princípio de proteção do empregado para o Brasil. 2014. Disponível em: https://repositorio.ufsc.br/bitstream/ handle/123456789/128693/331752.pdf. Acesso em: 26 ago. 2018.

Recebido em: 25 jun. 2019.

Aceito em: 17 jan. 2020. 